\title{
Immigration policy, foreign agricultural labor, and exit intentions in the United States dairy industry
}

\author{
D. Susanto, ${ }^{1}$ C. P. Rosson, D. P. Anderson, and F. J. Adcock \\ Department of Agricultural Economics, Texas A\&M University, College Station 77843-2124
}

\section{ABSTRACT}

United States agriculture is dependent on foreign labor. Current US immigration policies have been alleged to disrupt agricultural labor availability, particularly that of hired foreign labor. A national survey of dairy farmers across herd sizes and regions of the United States was conducted and the results were used to estimate the extent to which hired foreign labor dependency will affect exit intentions in dairy farming. This study found that the expected probability of exit from dairy farming increased as the use of hired foreign labor intensified. But the expected probability of exit also decreased rapidly as herd sizes got larger. Given the immigration policy currently in place, farmers expecting labor shortages in the future are expected to experience greater tendency to exit the industry.

Key words: immigration, foreign labor, exit intention, dairy industry

\section{INTRODUCTION}

The number of US dairy operations has declined in recent decades. Data indicate that the number of dairy operations decreased about $32 \%$ from 2000 to 2007 (National Agricultural Statistics Service, 2009). Notably, dairy farms with fewer than 500 cows per farm have decreased whereas those with 500 or more cows have increased, with a substantial increase occurring in the farms with more than 2,000 cows. Of those farm sizes that decreased, farms with fewer than 30 cows disappeared rapidly, and farms with between 30 and 200 cows decreased by approximately 30\% (MacDonald et al., 2007).

Several studies have been conducted to identify and analyze factors affecting dairy farmers' exit decisions (e.g., Chavas and Magand, 1988; Zepeda, 1995; Rahelizatovo and Gillespie, 1999; Bragg and Dalton, 2004; Foltz, 2004; Tauer, 2006). Variables such as prices, feed costs, age, employment rates, yield, education, and

Received September 14, 2009.

Accepted December 7, 2009.

${ }^{1}$ Corresponding author: dsusanto@ag.tamu.edu government programs, among others, have provided evidence of the diversity of factors that affect exit decisions from dairying. Recent developments in immigration policy and labor shortages have also been associated with exit decisions. However, these factors have not been fully analyzed to determine to what degree they contribute to exit decisions.

The importance of immigration policies to the agricultural sector is obvious because of agriculture's dependence on foreign workers. According to the current population survey, about $40 \%$ of all farm workers are foreign-born and lack US citizenship (Economic Research Service, 2008). The number of hired workers on US farms has shown a declining trend since 2000 and even earlier (National Agricultural Statistics Service, undated; various issues). Some believe that the decreasing labor force comes from immigration-related policies such as employment verification and enforcement activities (Levine, 2008). This disruption in agricultural labor can significantly affect agricultural production and result in severe financial problems, thereby stimulating exit intentions. Recent labor shortages in the agricultural sector, for example, have resulted in an increased average wage and consequently higher production costs. [The April 2008 data show that hired workers received an average wage of $\$ 10.60 / \mathrm{h}$ compared with $\$ 10.20 / \mathrm{h}$ 1 yr earlier; livestock workers earned $\$ 10.32 / \mathrm{h}$, an increase of $\$ 0.73$ from 1 yr earlier (National Agricultural Statistics Service, 2008). From an economic point of view, an increase in wages as the number of hired workers decreased over the same period indicates that the decrease in worker numbers was caused by a tight labor supply rather than a decrease in demand for farm labor.] A report by the American Farm Bureau Federation (2006) indicated that with the elimination of migrant labor, US agriculture would suffer annual loses of $\$ 1.5$ to 5.0 billion and about 10 to $20 \%$ of fruit and vegetable producers would go out of business.

The objective of this study was to analyze the likely effects of labor shortages and immigration policies on exit intentions of US dairy farms using a binary probit model. This study uses a recent survey of 5,005 dairy farmers from different herd sizes across the United States. The results of the study provide useful infor- 
mation for evaluating recent concerns regarding immigration policy and labor shortage effects on US dairy farms, particularly those related to exit decisions. Furthermore, given recent debate on immigration policy, the results also provide empirical evidence of what the likely effects would be if US immigration policy remains unchanged or becomes more stringent.

\section{Literature Review}

Different models have been used to analyze exit decisions in the dairy industry, with the most applied model being a Markov chain analysis. Among studies within the context of Markovian model are Chavas and Magand (1988), Zepeda (1995), Rahelizatovo and Gillespie (1999), and Stokes (2006) for the dairy farms in the United States. In general, the studies agree that there have been structural changes in the dairy industry across the United States, with small farms tending to exit at a faster rate in response to different factors. Chavas and Magand (1988) found that US dairy farms with fewer than 50 cows are not size efficient because their numbers decline in all regions. Also, higher milk prices increased the number of farms in all farm size categories but varied by regions. Zepeda (1995) projected that small and medium farms in Wisconsin would not exist in the long run. Furthermore, she argued that structural change may take place because of reasons other than prices, such as size economies, technological change, or policies not captured in her model.

Similarly, Rahelizatovo and Gillespie (1999) found that several factors have significantly affected the structure of the Louisiana dairy industry. These include milk and input prices, technology, agricultural policies such as Milk Diversion Program and Dairy Termination Program, and farmers' financial conditions. Environmental concerns are also found to be of major importance to most livestock farmers in changing farm structure. The most recent study using a Markovian model conducted by Stokes (2006) suggested that although milk prices, milk price volatility, land prices, and government policy have pervasive effects on exit from dairying in Pennsylvania, the value of agricultural land in Pennsylvania was found to be the most important factor contributing to the decline in the number of dairy farms. The estimated rate of decline of the dairy farms, which primarily occur in smaller operations, is about 2.0 to $2.5 \%$ annually over the next $20 \mathrm{yr}$.

Recently, sunk cost models, where farm exit and entry are modeled as a function of sunk costs, and real option models, where entry (exit) decisions are modeled as a call (put) option, have been applied to entry and exit decisions in the US dairy industry. An example of sunk cost model is given by Foltz (2004), who found that price premiums and lower price variances helped farmers stay in business. The study also suggested that there are other significant forces, both on the farm and in the local communities, that are pushing farms to exit. Tauer (2006) developed a real option model to examine the level of milk prices that encouraged farmers to exit and enter the industry given the investment and structure of different types of New York dairy farms. He found that price bounds existed where exit (entry) does not occur until milk price moves below (above) the lower (upper) price bound. The price bounds normally vary by type of farm. Small dairy farms will exit at a higher price than large farms, and a higher price is needed to induce entry by a small dairy farm.

A binary choice regression model was also recently used by Bragg and Dalton (2004) to examine the factor affecting the decision to exit dairy farming. Using a sample of 64 Maine dairy farmers, they estimated exit decision on 3 categories of explanatory variables: demographic, efficiency, and opportunity costs. In general they found that older producers, higher off-farm income, lower returns over variable cost, and greater diversification of farm income were more likely associated with a decision to leave dairy farming.

\section{MATERIALS AND METHODS}

Between June and August 2008, the Center for North American Studies, Department of Agricultural Economics, Texas A\&M University (College Station), conducted a national survey of dairy farmers to analyze the economic impact of immigration on US dairy farms. The survey comprised 5,005 dairy farmers from different herd sizes across the United States. A total of 2,071 questionnaires were returned either fully or partially completed for an overall survey response rate of $41.4 \%$. Of the 2,071 returned questionnaires, a total of 1,081 were used in this analysis. This number represents $21.6 \%$ of survey recipients and $52.2 \%$ of respondents. Factors that decreased the number of respondents in this study include the exclusion of small dairy farmers with fewer than 50 cows and the fact that some respondents likely felt uncomfortable answering questions related to sensitive issues surrounding hired foreign labor.

In this analysis, dairy farms were categorized into 4 sizes based on the number of cows in the farm: size $1=$ 50-199 cows, size $2=200-499$ cows, size $3=500-999$ cows, and size $4=500$ or more cows. Farms with fewer than 50 cows were excluded from the analysis because they were considered not economically viable. The distribution of the sample across herd sizes shows that $59 \%$ of samples were classified as size $1,18 \%$ as size 2 , $11 \%$ as size 3 , and $12 \%$ as size 4 . 
As discussed previously, various factors can cause farmers to exit from dairying. These factors may include milk:feed price ratio, milk prices, milk price volatility, productivity (milk production per cow), interest rates, debt:equity ratio, land values, government policies, and population density, among others. Recently, labor shortages in the agricultural sector, including the dairy industry, have been of concern and may stimulate exit decisions. One particular reason why foreign labor can affect exit decisions from dairying is because the dairy industry has become increasingly dependent on immigrant workers. For example, it is estimated that foreign labor represents $41 \%$ of the dairy workforce, and a $50 \%$ reduction of this labor category would result in the loss of 2,266 dairy farms (Rosson et al., 2009).

Labor shortages have frequently been associated with the recent development of immigration-related policies such as E-Verify, no-match rules, and, to some extent, the raids by Immigration and Customs Enforcement. However, these factors (i.e., labor shortages) have not been fully analyzed as to what degree they contribute to exit decisions. This study focused on analyzing how foreign labor affects exit intentions in the dairy industry.

This analysis used a binary probit model to estimate the probability of farmers' intention of exiting dairy farming. The use of the probit model was motivated by the fact that our measure of the dependent variable is in the form of a binary variable reflecting dairy farmers' intention of exiting dairy farming. Given its structure, the probit model provides a reasonable method of projecting the probability of exit intention given certain changes in the explanatory variables.

The current study used current survey data of dairy farmers across the United States. It is important to mention that the survey question representing the dependent variable (i.e., exit intention) was designed in such a way that it reflected the current state of immigration policies. Therefore, the empirical model does not directly or explicitly include variables for immigration policies. Similarly, a variable reflecting expected labor shortages to be discussed in the following section was also framed under the assumption that the current immigration policies remain.

Specifically, the dependent variable $\left(y_{i}\right)$ was constructed so that each respondent was given the same question regarding his or her intention of exiting dairy farming in the future (i.e., the next 3-5 yr) given the current state of immigration policies. The variable $y_{i}$, therefore, reflects dairy producers' intention to exit or not to exit from dairy farming and takes the value of 1 if a farmer intends to exit and 0 otherwise. The structure of the dependent variable permits the use of a binary probit model that can be written as

$$
y_{i}^{*}=\mathbf{x}_{i}^{\prime} \boldsymbol{\beta}+\varepsilon_{i} .
$$

The dependent variable $\left(y_{i}^{*}\right)$ is usually referred to as the latent variable (Long, 1997; Greene, 2008) that indexes the producer's intention to exit dairy farming; $\mathbf{x}_{i}^{\prime}$ is a row vector of the explanatory variables; $\boldsymbol{\beta}$ is a column vector of parameters that reflects the effect of changes in $\mathbf{x}_{i}^{\prime}$ on the probability with the first element being intercept $\beta_{0}$; and $\varepsilon_{i}$ is the stochastic error term, with $\varepsilon_{i} \sim N(0,1)$. The latent variable $\left(y_{i}^{*}\right)$ is unobserved but can be linked to the observed binary variable as follows:

$$
y_{i}=\left\{\begin{array}{ll}
1 & \text { if } y_{i}^{*} \geq 0 \\
0 & \text { if } y_{i}^{*}<0
\end{array} .\right.
$$

A standard procedure to estimate equation [1] is to use maximum likelihood estimation (see Amemiya, 1985; Long, 1997; Greene, 2008).

The independent variables included in the model were the number of years farmers have engaged in dairy farming (LENGTH), farm ownership (FOWN), the ratio of the number of hired foreign workers to total hired workers (FLABOR), farmers' expectations regarding future labor shortages given the current status of US immigration policy (ELABOR), the share of nondairy income (NDINC), the number of dairy cows on the farm (NCOWS), and herd size (SIZE). Descriptions of variables are given in Table 1.

The effect of variable LENGTH cannot be determined a priori. First, LENGTH was expected to affect exit decisions in that the longer the farmer has engaged in dairy farming the higher the probability of exit. This can partly be explained in that exiting dairy farming is relatively less costly in terms of capital liquidation because capital structure (such as buildings and equipment) becomes relatively obsolete as the dairy farms get older. On the other hand, LENGTH can be negatively related to exit intentions as suggested by Hoppe and Korb (2006). That is, younger, more recent entrants are more likely to exit than older, more established farms. Further discussions on variable LENGTH are given in the Results and Discussion section.

Of primary interest in this study were FLABOR and ELABOR. The variable FLABOR describes the dependency level of dairy farming on foreign workers. We used the ratio because it gives more meaningful measure of labor dependency than the absolute number. [We estimated the model using the number of hired 
Table 1. Definitions for dependent and independent variables

\begin{tabular}{|c|c|}
\hline Variable & Description \\
\hline LENGTH & Length of time farmer has been in dairy farming (years) \\
\hline ELABOR & $\begin{array}{l}\text { Farmers' expectation about labor shortage in the future given the current state of immigration } \\
\text { policies (ELABOR }=1 \text { if a farmer expected labor shortage; ELABOR }=0 \text { otherwise) }\end{array}$ \\
\hline FOWN & Farm ownership (FOWN = 1 if a farm is owned; FOWN $=0$ otherwise, such as rent or lease) \\
\hline SIZE & $\begin{array}{l}\text { Farm sizes based on the number of cows in the farm }(1=50-199 \text { cows, } 2=200-499 \text { cows, } \\
3=500-999 \text { cows; } 4=1,000 \text { or more cows }) . \text { Farms with fewer than } 50 \text { cows were excluded } \\
\text { from the analysis because they are considered not economically viable. }\end{array}$ \\
\hline
\end{tabular}

foreign labor and domestic labor, but the results were less superior (in terms of expected signs and statistical tests) than the model that used ratio variable.] For example, a farmer hiring 10 foreign laborers is not necessarily more dependent on foreign labor than a farmer hiring 5 foreign laborers. But it is true that a farmer hiring 10 foreign laborers out of 25 total hired laborers is relatively less dependent on foreign labor than a farmer hiring 5 foreign laborers out of a total of 7 total hired laborers. It was expected that an individual producer with high FLABOR would tend to be inclined to exit dairy farming given current immigration policies. [It has been argued that recent activities from Bureau of Citizenship and Immigration Services and Bureau of Immigration and Customs Enforcement to step up employment verification and enforcement activities have disrupted the agricultural workforce (see Levine, 2008), particularly foreign agricultural labor.] The variable ELABOR describes farmer's expectations about labor shortages in the future. This variable was measured by asking an individual farmer whether he or she anticipates a shortage of workers for dairy operation in the near future if current immigration policies remain in place. It was expected that ELABOR would be positively correlated with exit intentions.

The variable FOWNS is less likely to drive exit intentions, meaning that farmer-owned operations are less likely to exit dairy farming than non-farmer-owned operations because farmer-owned operations face liquidation of fixed capital such as buildings and equipment. Meanwhile, the higher the NDINC the less likely the farmer is to exit dairy farming because dairy farmers may perceive dairying as a lifestyle rather than a business. Therefore, we expected a negative relationship between NDINC and the exit intention. The variables NCOWS and SIZE were both intended to measure the effects of herd size on exit intentions. The variable NCOWS is a continuous random variable that indicates the number of cows on a farm, whereas SIZE represents herd sizes based on specific categories and a range of cow numbers. The 2 variables were included in the model as alternatives to each other and were expected to have negative effects on exit intentions because of the high liquidation costs associated with larger farms.

\section{RESULTS AND DISCUSSION}

\section{Econometric Results}

Results from the probit model estimates of farmers' intentions to exit dairy farming are presented in Table 2. Specification 1 reports the model that included NCOWS and specification 2 includes SIZE. The columns next to the parameter estimates provide the marginal effects of each variable. As shown, the estimated models yielded statistically significant parameters for LENGTH, FLABOR, ELABOR, and NCOWS and SIZE. Two variables, FOWN and NDINC, were not significant. The 2 specifications generally yielded similar estimates in both parameters and marginal effects, suggesting that specifying herd sizes in terms of NCOWS and SIZE provided consistent results. For practical discussion, we focus on the results given in specification 2 .

The parameter estimate of LENGTH was positive, suggesting that the longer the farmer is engaged in dairy farming, the higher the probability of exit intention. But the corresponding estimate of the marginal effect was very small (0.006). This means that with a 1 -yr increase in the mean value of time in dairy farming, the probability of exiting increased by $0.6 \%$. This finding is not consistent with those reported in Hoppe and Korb (2006), which suggest the exit probability is inversely related to the age of the business. It should be noted, however, that the study by Hoppe and Korb (2006) did not specifically analyze dairy farming but rather farms in general. Therefore, the effects of business age on exit intentions might be different because of the uniqueness of the dairy industry. The positive 
Table 2. Probit estimation of dairy farmer exit ${ }^{1}$

\begin{tabular}{|c|c|c|c|c|}
\hline Variable $^{2}$ & \multicolumn{2}{|c|}{ Specification 1} & \multicolumn{2}{|c|}{ Specification 2} \\
\hline Intercept & $-0.169(0.331)$ & & $-1.352^{*}(0.188)$ & \\
\hline FLABOR & $0.402 *(0.155)$ & $0.096^{*}(0.037)$ & $0.386^{*}(0.150)$ & $0.092 *(0.036)$ \\
\hline ELABOR & $0.379 *(0.115)$ & $0.101 *(0.034)$ & $0.358^{*}(0.115)$ & $0.095 *(0.033)$ \\
\hline FOWN & $-0.033(0.124)$ & $-0.008(0.030)$ & $-0.034(0.124)$ & $-0.008(0.030)$ \\
\hline Log likelihood & -462.99 & & -461.52 & \\
\hline Likelihood ratio $\chi^{2}$ & 100.46 & & 103.41 & \\
\hline Pseudo $\mathrm{R}^{2}$ & 0.098 & & 0.101 & \\
\hline No. of samples & 1,081 & & 1,081 & \\
\hline
\end{tabular}

${ }^{1}$ Numbers in parentheses are estimated SE. Specification 1 reports the model that includes NCOWS and specification 2 includes SIZE. Dash indicates that variable is not included in the model.

${ }^{2}$ LENGTH $=$ number of years farmers have engaged in dairy farming; FLABOR $=$ the ratio of the number of hired foreign workers to total hired workers; ELABOR = farmers' expectations regarding future labor shortages given the current status of US immigration policy; FOWN = farm ownership; NCOWS = number of dairy cows on the farm; NDINC = share of nondairy income; SIZE $=$ herd size.

*Significant at the $1 \%$ level.

sign of variable LENGTH in this study can partly be explained by the fact that capital structure (such as buildings and equipment) becomes relatively obsolete over time, suggesting that exiting dairy farming is relatively less costly in terms of capital liquidation.

An alternative explanation for the positive sign of LENGTH is that, although it is not necessarily true, LENGTH might proxy for dairy farmer age that is not captured in the model. Therefore, this argument might suggest that a larger value of LENGTH is caused by the fact that the dairy farmer is older. Older farmers often downsize their operations and disinvest as they exit farming (Bragg and Dalton, 2004; Hoppe and Korb, 2006).

The positive sign of FLABOR suggests that higher hired foreign labor relative to total hired labor increases the probability of exit intentions from dairy farming. Although dairy farmers may substitute domestic labor for foreign labor if, in fact, labor shortages did occur, this study provides statistical evidence of the dependency of US dairy farms on hired foreign labor. As shown in Table 2, the parameter estimate of FLABOR was significant at the $5 \%$ level, with its estimated marginal effect of 0.096 .

Similarly, ELABOR was positive, suggesting that having an expected labor shortage in the future increases the probability of exiting dairy farming. Given the structure of the question that was designed under the state of current immigration policies, ELABOR suggests the important effects of immigration policies on exit intentions. The estimated marginal effect was 0.101, suggesting that having expected labor shortages in the future as a result of the current immigration policies increases the probability of exit intentions by $10 \%$.
Based on these 2 labor-related variables, we conclude that both foreign labor and immigration policy are important determinants of intentions to exit intentions dairy farming.

The variable SIZE was found to be significant with a negative sign. This suggests that the bigger the farm size, the lower the probability of the exit intention. These findings are consistent with the results given by Hoppe and Korb (2006), where exit probability was found to be particularly low for large farms. Following Hoppe and Korb (2006), it is likely that the decreasing exit intention in large dairy farms explains the growing concentration of production sizes, particularly in California and the southwest regions of the United States. Both FOWN and NDINC lack statistical significance.

\section{Predicted Probability}

The estimated parameters of the probit model do not provide directly useful information for understanding the relationship between the independent variables and the outcome (Greene, 2003; Long and Freese, 2006). The estimated parameters provide only the direction of the effect, not the magnitude. The marginal effects provide better information about the relationships between independent variables and the dependent variable. But, the marginal effects are still limited in that it is difficult to translate the marginal effects into the change in the predicted probability that will occur if there is a discrete change in independent variables. In addition, marginal effects normally calculated at the mean values usually cause problems for discrete variables (Long, 1997). Substantive, meaningful interpretations are normally based on predicted probabilities for 
Table 3. Predicted probability of intention to exit dairy farming based on labor shortage expectation and level of hired foreign labor ${ }^{1,2}$

\begin{tabular}{|c|c|c|c|c|}
\hline State of interest ${ }^{3}$ & Size 1 & Size 2 & Size 3 & Size 4 \\
\hline Not hiring foreign labor at all $(\mathrm{FLABOR}=0.00)$ & 0.28 & 0.17 & 0.09 & 0.04 \\
\hline Low level of hired foreign labor $($ FLABOR $=0.22)$ & 0.31 & 0.19 & 0.10 & 0.05 \\
\hline High level of hired foreign labor $($ FLABOR = 0.93) & 0.41 & 0.27 & 0.16 & 0.09 \\
\hline \multicolumn{5}{|l|}{ Farmers not expecting labor shortage in the future } \\
\hline Not hiring foreign labor at all $($ FLABOR $=0.00)$ & 0.17 & 0.09 & 0.04 & 0.02 \\
\hline High level of hired foreign labor $($ FLABOR $=0.93)$ & 0.28 & 0.17 & 0.09 & 0.04 \\
\hline
\end{tabular}

${ }^{1}$ All probabilities are calculated using model specification 2 for farm owned, with LENGTH (number of years farmers have engaged in dairy farming) and NDINC (share of nondairy income) as the mean value. The number 0.28 is interpreted as the probability of exit intention for size 1 farmers who expected labor shortages in the future but did not hire foreign labor at all.

${ }^{2}$ Size $1=50-199$ cows, size $2=200-499$ cows, size $3=500-999$ cows, and size $4=500$ or more cows. Farms with fewer than 50 cows were excluded from the analysis because they are not economically viable.

${ }^{3} \mathrm{FLABOR}=$ the ratio of the number of hired foreign workers to total hired workers.

combinations of several variables of interest because they provide better information about the factors affecting the probability of occurrence (i.e., intentions to exit dairy farming). Effects of specific combinations of variables of interest on the probability of intentions to exit dairy farming are shown in Table 3 .

Table 4 shows the number of survey respondents in each category based on labor shortage expectation and farm size. For example, farmers with farms of size 3 who owned their dairy farm and did not expect a labor shortage but did hire more than $73 \%$ foreign labor represented 36 of the survey respondents. This data, combined with the probabilities in Table 3, can be used to estimate the number of dairy farms that intend to exit the industry.

Table 3 contains the probability estimates of intentions to exit dairy farming for owned farms that expect and do not expect labor shortages in the future. Probabilities of exit intention with 4 levels of hired foreign labor and 4 levels of herd sizes were evaluated. The 4 levels of FLABOR were 1) no-hired foreign labor (FLA$\mathrm{BOR}=0.00), 2)$ low level of hired foreign labor (FLA$\mathrm{BOR}=0.22)$, 3) medium level of hired foreign labor $($ FLABOR $=0.53)$, and 4$)$ high level of hired foreign labor $(\mathrm{FLABOR}=0.93)$. Four levels were chosen based on the estimated standard deviation of FLABOR.

The number 0.28 in the first row and first column of Table 3 suggests that the probability of intention to exit dairy farming for size 1 farms that expect labor shortages and did not hire foreign labor (FLABOR = 0.00 ) is $28 \%$. Stated differently, we estimated that $28 \%$ of the farms of this type will exit dairy farming in the next 3 to 5 yr given the current immigration policies. The number of farms sampled in the survey that were

Table 4. Number of farms in a sample of 1,081 in combinations of farm size and ownership and foreign labor expectations ${ }^{1}$

\begin{tabular}{|c|c|c|c|c|c|c|c|c|c|c|}
\hline Farm size $^{2}$ and ownership & \multicolumn{5}{|c|}{ No labor shortage } & \multicolumn{5}{|c|}{ Labor shortage } \\
\hline \multicolumn{11}{|l|}{ Size 1} \\
\hline Nonowned farm & 84 & 2 & 8 & 6 & 100 & 18 & 1 & 2 & 2 & 23 \\
\hline \multicolumn{11}{|l|}{ Size 2} \\
\hline Owned farm & 44 & 11 & 30 & 35 & 120 & 8 & 4 & 12 & 10 & 34 \\
\hline Owned farm & 5 & 1 & 27 & 36 & 69 & 1 & 0 & 3 & 23 & 27 \\
\hline Nonowned farm & 0 & 2 & 3 & 10 & 15 & 0 & 0 & 0 & 5 & 5 \\
\hline \multicolumn{11}{|l|}{ Size 4} \\
\hline Owned farm & 2 & 3 & 7 & 57 & 69 & 1 & 0 & 7 & 20 & 28 \\
\hline Nonowned farm & 2 & 0 & 3 & 21 & 26 & 0 & 0 & 2 & 4 & 6 \\
\hline Total & 515 & 24 & 111 & 203 & 874 & 90 & 7 & 36 & 73 & 207 \\
\hline
\end{tabular}

${ }^{1} 0=$ farm with no hired foreign labor $(\mathrm{FLABOR}=0.00) ; 1=$ farm with hired foreign labor $(0<$ FLABOR $<0.32) ; 2=$ farm with hired foreign labor $(0.32<$ FLABOR $\leq 0.73) ; 3=$ farm with hired foreign labor $($ FLABOR $>0.73)$. FLABOR $=$ ratio between hired foreign labor and total hired labor. The average of FLABOR for categories 1, 2, and 3 are $0.22,0.53$, and 0.93 , respectively.

${ }^{2}$ Size $1=50-199$ cows, size $2=200-499$ cows, size $3=500-999$ cows, and size $4=500$ or more cows. Farms with fewer than 50 cows were excluded from the analysis because they are not economically viable. 
placed into this size and foreign labor category was 58 (Table 4). Based on the estimated probabilities, we would expect that 16 farms out of the sample would exit dairy farming in the next 3 to $5 \mathrm{yr}$. As the herd size gets larger, the estimated probability of exit intention decreases, meaning that farms with larger herds are less likely to exit dairy farming than farms with smaller herds. The probability of exit intention for herd size 4 (>999 cows) that did not hire foreign labor is almost zero (0.04), a significant decrease from size 1 farms. These findings support the reports given in Hoppe and Korb (2006).

The probabilities in Table 3 also indicate that as FLABOR increases the expected probability of exit intention increases. Given previous discussions, the results suggest that the expected probability of exit from dairy farming increases as the use of hired foreign labor intensifies, but decreases rapidly as herd sizes get larger. These findings may stimulate a conflicting notion that larger farms are more dependent on foreign labor but at the same time are less likely than small farms to go out of business. There are at least 2 possible reasons for this. First, the effect of losing any hired foreign labor on a small farms' efficiency is greater than that of a similar labor loss on larger farms because larger farms are better able to absorb labor losses. For example, if a small farm has 3 hired workers, then loses 1 and cannot replace him, it results in a larger consequence than if a large farm has 10 hired workers and loses 1 . Second, given that larger farms normally operate on a lower cost structure, they tend to be able to absorb higher costs because of economies of scale, giving them more economic resiliency than smaller farms. The larger farms also seem to be able to acquire replacement labor easier than smaller farms, possibly by paying higher wages or offering nonwage benefits such as housing, insurance, and use of a vehicle, or doing both. Larger farms may be more able to afford higher wages and nonwage benefits because of greater productivity than smaller farms.

Other possible explanations can be drawn from Table 3. As shown, the rate of increase in expected probability of exit intention as the relative use of hired foreign labor increases was lower than the rate of decrease in the expected probability of exit intention as herd sizes increased. For example, the probability of exit for a size 1 farm increases from 0.28 to 0.41 as the level of hired foreign labor increases, for a change of 13 percentage points. But for a farm with a high level of hired labor, size changes the exit probability from 0.41 to 0.09 , a decrease of 32 percentage points. Clearly, this suggests that SIZE supersedes FLABOR in terms of effects on exit intentions.
The relatively larger effects of SIZE compared with foreign labor dependence may suggest that economies of scale and size may have relatively more bearing on the exit decision than labor. But, labor and expectations of labor shortages can lead to exit as well.

The bottom portion of Table 3 shows the expected probability of exit intentions for a group of dairy farmers that did not expect labor shortages in the future. The results are similar to those that did not expect labor shortages in that the larger the herd size the less likely that the farm would exit dairy farming. The greater the value of FLABOR (more intensive use of hired foreign labor), the higher the expected probability of exiting dairy farming. Compared with the results for those expecting labor shortages, the expected probability of exit intentions for farmers not expecting labor shortages is consistently smaller. For example, the expected probability of exit intentions for farmers of size 1 farms that do not expect labor shortages in the future is 0.20 compared with 0.31 for farmers that expect labor shortages. This suggests that farms with no expected labor shortage in the future are less likely to exit dairy farming than those with an expected labor shortage.

\section{Policy Implication}

Given that the survey was conducted under current immigration policies, findings from this study reflect the important effects of these policies and agricultural labor, particularly foreign labor, on exit intentions of dairy farms. Immigration policy options, such as comprehensive immigration reform, could have important implications for the availability and stability of the dairy farm workforce and, ultimately, the economic survival of many dairy farms. Analyzing current immigration policies, including temporary worker programs and increased enforcement of existing immigration regulations, also merits consideration because they affect foreign labor availability.

\section{CONCLUSIONS}

The results of this study provide significant evidence of the impact of the ratio of hired foreign labor to total hired labor on the probability of exit intentions, where a higher ratio increases the probability of exit intentions from dairying. The estimated marginal effect suggests that having expected labor shortages in the future as a result of the current immigration policies increases the probability of exit intentions by $10 \%$. Herd sizes are found to be inversely related to the probability of exit intentions. These results highlight 2 distinct points: the expected probability of exit intention increases as the 
use of hired foreign labor increases, as shown within specific farm size, but at the same time, the expected probability decreases as herd size expands. The effects of herd size seem to supersede the effects of the ratio of foreign labor to total labor.

\section{ACKNOWLEDGMENTS}

The authors thank the anonymous reviewers and the editors of Journal of Dairy Science for their constructive comments. The survey and related research were conducted under contract for National Milk Producers Federation (Arlington, VA). Funding for this work was also partially supported by USDA Cooperative State Research, Education and Extension Service (Washington, DC) Federal Research Administration Grant \#2008-03223.

\section{REFERENCES}

Amemiya, T. 1985. Advanced Econometrics. Harvard University Press, Boston, MA

American Farm Bureau Federation. 2006. Impact of Migrant Labor on the Agricultural Sector. Economic Analysis Team, Washington, DC.

Bragg, L. A., and T. J. Dalton. 2004. Factors affecting the decision to exit dairy farming: A two-stage regression analysis. J. Dairy Sci. 87:3092-3098.

Chavas, J., and G. Magand. 1988. A dynamic analysis of the size distribution of firms: The case of the U.S. dairy industry. Agribusiness 4:315-329.

Economic Research Service. 2008. Rural Labor and Education: Farm Labor. USDA, Washington, DC. http://www.ers.usda.gov/ Briefing/LaborAndEducation/farmlabor.htm Accessed June 15, 2008.

Foltz, J. D. 2004. Entry, exit, and farm size: Assessing an experiment in dairy price policy. Am. J. Agric. Econ. 86:594-604.

Greene, W. H. 2008. Econometric Analysis. 6th ed. Prentice Hall, Upper Saddle River, NJ.
Hoppe, R. A., and P. Korb. 2006. Understanding U.S. Farm Exits. Economic research report no. 21. Economic Research Service, USDA, Washington, DC.

Levine, L. 2008. Farm Labor Shortages and Immigration Policy. CRS Report for Congress. Order Code RL30395. Congressional Research Service, Washington, DC.

Long, J. S. 1997. Regression Models for Categorical and Limited Dependent Variables. Sage Publications, Thousand Oaks, CA.

Long, J. S., and J. Freese. 2006. Regression Models for Categorical Dependent Variables Using Stata. 2nd ed. Stata Press, College Station, TX.

MacDonald, J. M., E. J. O'Donoghue, W. D. McBride, R. F. Nehring, C. L. Sandretto, and R. Mosheim. 2007. Profits, Costs, and the Changing Structure of Dairy Farming. Economic research report no. 47. Economic Research Service, USDA, Washington, DC

National Agricultural Statistics Service. 2009. Quick Statistics Database: U.S. and All State Dairy Data (from various years). http://www.nass.usda.gov/QuickStats/Create_Federal_All.jsp Accessed Mar. 25, 2009.

National Agricultural Statistics Service. Undated. Farm Labor (various issues). http://usda.mannlib.cornell.edu/MannUsda/ viewDocumentInfo.do?documentID=1063 Accessed Mar. 25, 2009 .

National Agricultural Statistics Service. 2008. Farm Labor. http:// usda.mannlib.cornell.edu/usda/nass/FarmLabo//2000s/2008/ FarmLabo-05-16-2008.pdf Accessed Feb. 19, 2009.

Rahelizatovo, N. C., and G. F. Gillespie. 1999. Dairy farm size, entry, and exit in a declining production region. J. Agric. Appl. Econ. $31: 333-347$

Rosson, C. P., F. J. Adcock, D. Susanto, and D. Anderson. 2009. The Economic Impacts of Immigration on U.S. Dairy Farms. A Survey Report Conducted by Texas Agrilife Research, Center for North American Studies (CNAS), and National Milk Producers Federation (NMPF). National Milk Producers Federation, Washington, DC. http://nmpf.org Accessed Dec. 2, 2009.

Stokes, J. R. 2006. Entry, exit, and structural change in Pennsylvania's dairy sector. Agric. Resource Econ. Rev. 35:357-373.

Tauer, L. W. 2006. When to get in and out of dairy farming: A real option analysis. Am. J. Agric. Econ. 86:339-347.

Zepeda, L. 1995. Asymmetry and nonstationarity in the farm size distribution of Wisconsin milk producers: An aggregate analysis. Am. J. Agric. Econ. 77:837-852. 